\title{
Loucura e o trabalho: integralidade e cuidado em rede no SUS
}

\author{
Madness and work: comprehensiveness and network care in the SUS
}

Andréia De Conto Garbin (https://orcid.org/0000-0003-2787-7470) ${ }^{1}$

Arthur Chioro (https://orcid.org/0000-0001-7184-2342) ${ }^{2}$

Eliana Aparecida da Silva Pintor (https://orcid.org/0000-0002-2585-9116) ${ }^{3}$

Margarete dos Santos Marques (https://orcid.org/0000-0003-0391-6893) ${ }^{4}$

Maria Amélia Cunha Branco (https://orcid.org/0000-0001-9905-4620) ${ }^{5}$

Angela Aparecida Capozzolo (https://orcid.org/0000-0002-8049-1369) ${ }^{6}$

${ }^{1}$ Faculdade de Ciências Humanas e da Saúde, Pontifícia Universidade Católica de São Paulo. R. Monte Alegre 984, Perdizes. 05014-901. São Paulo SP

Brasil.andreiagarbin@

yahoo.com.br

${ }^{2}$ Departamento de Medicina

Preventiva, Escola Paulista

de Medicina, Universidade

Federal de São Paulo. São

Paulo SP Brasil.

${ }^{3}$ Secretaria Estadual de Saúde do Estado de São

Paulo. São Paulo SP Brasil.

${ }^{4}$ Universidade São Judas

Tadeu. São Paulo SP Brasil

${ }^{5}$ Secretaria Municipal de

Saúde de São Bernardo do

Campo. São Bernardo do

Campo SP Brasil.

${ }^{6}$ Departamento Saúde,

Clínica e Instituições,

Universidade Federal de São

Paulo. São Paulo SP Brasil.

\begin{abstract}
This paper addresses a local the Unified Health System (SUS) management experience that managed to implement networked care and took work as a determinant of cross-sectional health through the integrated action between actors in PHC and the Psychosocial Care and Occupational Health Networks. We monitored one automotive industry worker, whose work activity led him to illness due to inhalation of chemical substances. The theoretical framework and the analysis method are based on the recognition of the user-guide as an investigation strategy. The user-guide biography uncovered distress from the concrete life of the working man. The organic aspects that trigger a mental disorder have been trivialized or neglected in various services, in the understanding of the illness process that originated in their work. According to current work-related mental health studies, the results confirm the need for a contextualized work clinic, integration between services, intersectoral interventions per SUS guidelines, and public Mental Health and Occupational Health policies.
\end{abstract}

Key words Occupational health, Mental health, Integrated health service networks, Organic psychosis, User-guide
Resumo Oartigo aborda uma experiência de gestão local do Sistema Único de Saúde (SUS) que logrou implementar o cuidado em rede e tomou o trabalho como um determinante de saúde transversal, por meio da ação integrada entre atores dispostos na atenção básica e nas Redes de Atenção Psicossocial e de Saúde do Trabalhador. Fez-se o acompanhamento de um trabalhador de uma indústria automotiva, cuja atividade laboral o levou a desenvolver um processo de adoecimento por inalação de substâncias químicas. O referencial teórico e o método de análise sustentam-se no reconhecimento do usuário-guia como estratégia de investigação. A biografia do usuário-guia revelou um sofrimento apartado da vida concreta do homem trabalhador. Os aspectos orgânicos deflagradores de um transtorno mental foram banalizados ou negligenciados, em vários serviços, na compreensão do processo de adoecimento que teve origem no seu trabalho. Consoante aos estudos atuais em Saúde Mental relacionada ao Trabalho, os resultados ratificam a necessidade de uma clínica contextualizada do trabalho, da integração entre os serviços e das intervenções intersetoriais, de acordo com as diretrizes do SUS e as politicas públicas de Saúde Mental e de Saúde do Trabalhador.

Palavras-chave Saúde do trabalhador, Saúde mental, Redes integradas de serviços de saúde, Psicose orgânica, Usuário-guia 


\section{Introdução}

Investigações que tomam como objeto de estudo a situação vivenciada por um trabalhador não são uma novidade para o campo da saúde do trabalhador e em estudos que analisam os transtornos mentais relacionados ao trabalho ${ }^{1-3}$. A produção de Laurel e Noriega ${ }^{4}$ influenciou as experiências desenvolvidas no Brasil no campo da saúde do trabalhador, anteriores à estruturação do Sistema Único de Saúde (SUS) ${ }^{5,6}$ e estiveram sustentadas na prevenção e promoção da saúde com a participação dos trabalhadores, ancoradas na crítica ao modelo da medicina ocupacional e centradas no processo social do processo saúde-doença ${ }^{7,8}$. Os determinantes sociais foram incorporados à explicação sobre a saúde-doença da classe trabalhadora e a produção da saúde passou a ter foco no trabalho e no desgaste operário. Mas há uma ausência de investigações que tomem como objeto central de análise os caminhos que percorrem os trabalhadores nas redes de atenção do SUS e as estratégias de integração entre a Saúde do Trabalhador e outros pontos de atenção da rede para proporcionar a atenção integral ao trabalhador adoecido.

É na rede de saúde que se encontra o ambiente favorável para a articulação do cuidado em saúde mental e trabalho, que remontam às duas áreas programáticas e com origens comuns, Saúde do Trabalhador e Saúde Mental, mas desarticuladas e, tradicionalmente, estruturadas em unidades especializadas 9 .

As estratégias de cuidado e o cenário para circulação dos saberes ocorreram predominantemente em âmbito municipal, tendo como locus as Redes de Atenção à Saúde (RAS), que têm o objetivo de promover a integração da atenção e da gestão e garantir a efetividade e eficiência dos serviços aos usuários ${ }^{10}$. Neste cenário, se exercitou a articulação da Rede de Atenção Psicossocial (RAPS) com a Rede de Atenção Integral à Saúde do Trabalhador (RENAST), instituída em 2002, revista e ampliada posteriormente ${ }^{11}$.

A RENAST recepcionou os Centros de Referência em Saúde do Trabalhador (CEREST) existentes, assim como a RAPS os Centros de Atenção Psicossocial (CAPS). Essas duas redes guardaram características peculiares das políticas públicas que as instituíram, sendo a saúde mental, historicamente, alicerçada na reforma psiquiátrica ${ }^{12}$, e a saúde do trabalhador no reconhecimento do trabalho como determinante do processo saúde doença ${ }^{13}$. Em comum, o distanciamento das duas áreas em relação à atenção básica ${ }^{14,15}$.
A atuação integrada, articulando os diferentes pontos de atenção na rede de saúde, implica em superar as ações de saúde meramente orientadas por protocolos, fluxos e serviços de referência. Trata-se de criar novos dispositivos de cuidado que favoreçam a integralidade, impossível de ser oferecida e garantida em apenas um serviço. Cecílio ${ }^{16}$ pontua que o método epidemiológico e o olhar para o universo microssocial das necessidades em saúde favorecem a equidade e integralidade do cuidado em saúde.

A trajetória dos usuários pelos serviços de saúde descrita por fluxos e protocolos de atenção expõe a dimensão burocrática e não revela o dinamismo, os agenciamentos e os atravessamentos que ocorrem no percurso que se constrói na produção do cuidado. Agenciar remete à produção permanentemente da vida de modo coletivo e à criação de novos movimentos ${ }^{17}$. Deste modo, "os/as usuários/são redes vivas de si próprios, estes/as estão o tempo inteiro produzindo movimentos, elaborando saberes, construindo e partilhando cuidado"18, como um nômade em busca do cuidado pelas redes de serviços e com um forte protagonista de sua produção.

Em consonância com essas formulações, este artigo pretende, a partir do acompanhamento de um usuário trabalhador com sofrimento mental, identificar as redes acionadas para o seu cuidado e analisar uma experiência de gestão local do SUS que tomou o trabalho como um determinante de saúde transversal e buscou implementar o cuidado em rede, por meio da ação integrada entre atores dispostos na atenção básica, atenção especializada, saúde mental e vigilância em Saúde do Trabalhador. A utilização da categoria 'trabalho' reveste-se de importância estratégica para estudos destinados a analisar cuidados em saúde $e^{4,19}$ porque, embora tenha centralidade na vida das pessoas, na maioria das vezes consta como aspecto negligenciado pelas equipes de saúde, tanto nos serviços públicos como privados ${ }^{9,20}$.

\section{Metodologia}

A produção deste artigo, de caráter descritivoqualitativo, foi feita a partir da sistematização das experiências dos autores do artigo, tomadas como objeto de investigação e que se inserem no bojo da pesquisa intitulada: Políticas públicas e temas atuais do mundo do trabalho: impactos à saúde mental e subjetividade. A pesquisa está relacionada ao acompanhamento de um usuárioguia $^{17,18}$, foi escolhido um trabalhador de uma 
indústria automotiva, do setor de estofamentos. Sua atividade laboral resultou em um processo de adoecimento e na sua demissão, tendo sido reconhecido, inicialmente, como um usuário de saúde mental.

O critério de escolha deste usuário baseou-se no estudo sobre produção do acesso e barreira em saúde mental ${ }^{21}$, que realizou um percurso de investigação a partir dos usuários que mobilizavam a equipe, os considerados "louco muito louco" $^{\text {"21 }}$, dos múltiplos caminhos trilhados por eles nas redes de atenção e na construção do cuidado.

$\mathrm{O}$ nosso usuário-guia foi atendido em uma unidade básica de saúde de São Bernardo do Campo, município do Grande ABCD, localizado na região metropolitana de São Paulo, com mais de 800 mil habitantes e importante polo industrial do país. Possuía uma história marcada pelo sofrimento mental e comorbidades, expressas em oito códigos diferentes na Classificação Internacional de Doenças (CID) e em dez relatórios médicos e possibilitou que a equipe de saúde fosse dirigida pela sua trajetória. As interrogações sobre sua situação mobilizaram a equipe deste serviço para compreender melhor sua situação e para o seu projeto de cuidado.

O percurso metodológico consistiu na elaboração de reflexões e análises revisitando os registros de reuniões de equipe e entre profissionais de diferentes serviços, anotações em cadernos de campo e produções bibliográficas ${ }^{22,23}$. Após a leitura de cada registro foi construída uma síntese dos caminhos percorridos pelo usuário nas redes de atenção e do processo de cuidado e possibilitaram a construção de categorias de análise.

A análise permitiu o reconhecimento das situações práticas, o cotidiano de trabalho, a complexidade dos processos de trabalho, de saúde e de educação, bem como a participação e autonomia dos profissionais ${ }^{17}$.

A pesquisa a partir da qual esse artigo se insere foi aprovada pelo Comitê de Ética da Pontifícia Universidade Católica de São Paulo. Foram observados os procedimentos éticos necessários, com obtenção do consentimento livre e esclarecido dos entrevistados.

O usuário-guia tem 54 anos, pardo, $1,85 \mathrm{~m}$ de altura, magro, casado há cerca de 20 anos, tem um filho adolescente, condição socioeconômica baixa, cursou o ensino médio, nasceu e reside na região periférica do município. Por meio de encontros foi possível a reconstrução de sua história conhecer os seus deslocamentos na busca por cuidado, os modos nômades de movimentar-se na sua existência ${ }^{18,23}$.
O percurso desencontrado do usuário-guia pela rede de saúde pública e privada durou cerca de cinco anos. Um marco importante foi a perda do direito ao convênio médico, após ser demitido da empresa. O usuário se depara com a falta de trabalho, de dinheiro, de assistência pelo convênio, sem conseguir benefícios do INSS.

Foi em 2010 que o usuário passa a receber a atenção da equipe composta por médico da família, enfermeira, agente comunitária de saúde da Atenção Básica e apoiadores de diferentes núcleos profissionais: psicologia, serviço social, fisioterapia e farmácia, que tinham a atribuição de articular o cuidado, como será descrito adiante. As discussões das equipes, promovidas na articulação do cuidado em saúde mental, foram embasadas no entendimento socioecológico ${ }^{24} \mathrm{do}$ processo saúde-doença, que considera além dos fatores biológicos, os aspectos sociais, econômicos, culturais, políticos, ambientais, subjetivos na produção da saúde. Apoia-se na criação de ambientes favoráveis à saúde, na promoção da saúde individual e coletiva e no papel ativo dos sujeitos no processo de transformação social ${ }^{24}$. Ancorados na crítica ao modelo manicomial e hospitalocêntrico, a construção do cuidado apostou na consolidação das redes de atenção em saúde, nos vínculos conquistados por meio da escuta atenciosa, na corresponsabilização entre usuários, trabalhadores e gestores e no respeito à liberdade.

\section{Resultados e discussão}

O exercício experimentado, neste caso, exigiu um diálogo qualificado das equipes da Atenção Básica e dos diferentes serviços privilegiando o tratamento, a prevenção e a promoção da saúde do usuário-guia. Também possibilitou compreender que os agenciamentos a partir do usuário-guia podem revelar quando o trabalho enlouquece, reconhecer a produção do cuidado e refletir sobre as políticas e os dispositivos de gestão.

Neste contexto, foram construídas categorias de análise do processo de cuidado, conforme descrito a seguir.

\section{Usuário-guia: a identidade de trabalhador suplantada pela experiência da loucura}

Em meados de 2010, uma Unidade Básica de Saúde (UBS), de um bairro da periferia de São Bernardo do Campo, deparava-se com as novas demandas oriundas da reestruturação da atenção básica, que incorporava a Estratégia da Saúde 
da Família e o apoio de equipes multiprofissionais ${ }^{22,23}$. Ainda, a reorganização dos processos de trabalho levou à implantação do acolhimento como dispositivo organizativo visando uma atenção integral e humanizada ${ }^{25}$.

A aposta na estratégia do apoio multiprofissional visa potencializar a escuta das equipes de saúde, diante da complexidade dos casos, e a articulação do cuidado pela mobilização de diferentes saberes. $\mathrm{O}$ apoiador em saúde tem formação em um dos núcleos profissionais da área da saúde e transita pelos diversos serviços da rede agenciando conversas com intuito de compartilhar o cuidado e contribuir para a efetivação da integralidade $^{26}$. Por meio deste dispositivo ocorre uma ampliação do diálogo em rede para sustentar sua implementação ${ }^{27}$.

Nesse contexto, um usuário procurou atendimento na UBS porque precisava conseguir um benefício do INSS para sustentar sua família. No registro deste atendimento reverberava o pedido do usuário em sofrimento e nas informações sobre a história do seu adoecimento, o diagnóstico de esquizofrenia.

O usuário foi orientado a retornar dias depois para ser atendido pelas apoiadoras (assistente social e psicóloga) que o acolheram, escutando atentamente sua dor e sofrimento psíquico: $E u$ estou com distúrbio que não é enxergado, foi por causa do ambiente... tem muita coisa que eu não consigo entender.

O usuário foi colocado no radar da atenção da UBS, resultando na estruturação de um projeto terapêutico singular (PTS). A primeira etapa do PTS, o diagnóstico, permitiu reconhecer uma internação psiquiátrica em 2005 com diagnóstico de esquizofrenia. Foi no Natal de 2005 que tudo ficou estranho e depois me vi num hospital, amarrado e sendo medicado com injeções doloridas por pessoas que eu nunca vi na frente... Depois da internação, começou a ter dificuldade para lembrar-se das coisas e passou a anotar tudo em cadernos - datas dos atendimentos, remédios que tinha que tomar, as dificuldades que encontrava nos serviços e as injustiças vivenciadas. Outros dois diagnósticos o acompanhavam: asma e o comportamento acumulador (Síndrome de Diógenes).

A reconstrução de alguns percursos revela muitos momentos de sofrimento nos serviços, desde conseguir chegar aos lugares (distantes e em outros municípios e ir a pé por não conseguir permanecer em um ônibus ou carro) até esperar horas e ser atendido em o ambulatório de especialidades de uma Faculdade de Medicina (5 ou 6 horas) numa sala de aula com mais de 60 alunos.
Dificuldades para entender o seu sofrimento até acertar a medicação, falta de escuta, de acolhimento entre outros. O usuário referiu descaso e que foi maltratado nos serviços por onde andou. O surto se expressou com muitos risos exagerados e choros. Na época o pastor da igreja Batista que frequenta ajudou-o a conseguir atendimento num serviço particular espaço aberto. $\mathrm{O}$ médico desse serviço deu medicação pesada e ele ficou três meses dopado na cama. Não comia sozinho e só dormia. Aos poucos foi melhorando, mas foi desencadeado um quadro de síndrome do pânico. Os remédios eram caros, não conseguiam pagá-los e manter o atendimento.

Buscou o SUS, antes de 2010, e a unidade de saúde encaminhou para um ambulatório de especialidades de uma Faculdade de Medicina. Era atendido num auditório. Referiu sentir-se como um macaco num zoológico. Depois foi internado por 28 dias em um Hospital Estadual para acertar a medicação, pois estava intoxicado. Conta que sofreu bastante com a internação e, ainda, não permitiram que saísse para perícia médica do INSS e, por isso, perdeu o atendimento e não conseguiu o benefício. Refere que, em geral, os profissionais e as pessoas desvalorizam a sua fala, como se estivesse mentindo. Sentia-se ignorado e isso produzia sofrimento. Deparou-se com descasos e descuidados. Sentia que o remédio colaborava, mas não resolvia tudo, precisava falar e ser escutado.

Relativo à sua história ocupacional referiu empresas em que atuou com vínculo CLT como mecânico hidráulico e elétrico pneumático. $\mathrm{Na}$ última empresa trabalhou por cerca de cinco anos com produtos químicos em uma multinacional de estofamento automotivo. Segundo relato da esposa, sempre foi muito trabalhador e teve um surto psicótico, desencadeado após trabalhar muitas horas seguidas. Contava com o apoio social da esposa e filho, possuía casa própria e tinha sido demitido do trabalho em 2005.

Em 1999, o usuário trabalhava informalmente em ambiente com exposição a produtos químicos. No ano seguinte, em exame admissional para trabalhar em empresa do ramo automotivo teve como sentença "apto com restrições: não pode trabalhar na espuma".

Em 2003, começou a ter crises de asma severas, e em uma ocasião sofreu uma parada cardíaca e foi reanimado. Em 2004, após Prova de Função Pulmonar, recebeu o diagnóstico "distúrbio ventilatório obstrutivo leve".

Passou a apresentar constantes crises de asma e comportamentos antissociais que levaram ao 
diagnóstico de esquizofrenia. Em decorrência do seu estado de saúde foi demitido do trabalho.

Passou por diversos tipos de tratamentos e inúmeros profissionais, colecionando diferentes tipos de classificações de doenças (CIDs). Em 2008, realizou avaliação neuropsicológica que revelou "sinais de redução volumétrica córticosubcortical e com predomínio cortical”.

$\mathrm{O}$ percurso do usuário revelou o cuidado fragmentado, lacunas e muito sofrimento. A problematização do cuidado pela equipe desencadeou um processo de reflexão e análise com vistas a reorganizar a atenção e ofertar um cuidado integral. É nesse contexto que emergiu o usuário-guia, ${ }^{17}$ aquele que catalisa a integração entre os serviços e dispõe o diálogo interinstitucional.

Os encontros entre os trabalhadores de saúde dos diversos serviços possibilitaram uma compreensão sobre os complexos caminhos percorridos pelo usuário e propiciaram a elaboração de um conhecimento coletivo sobre a produção do cuidado. As narrativas possibilitaram a elaboração de diversos questionamentos e identificação de lacunas e, também, o estabelecimento de diferentes estratégias de cuidado. As narrativas produzidas tiveram como referencial o usuário.

Nas conversas das equipes de saúde na produção do cuidado emergiram as primeiras pistas sobre o processo de adoecimento vivenciado pelo usuário.

\section{O entrelaçamento das redes de atenção potencializado pela estratégia do apoio em saúde}

As primeiras conversas em rede envolvendo as equipes da UBS, CEREST e CAPS possibilitaram o exercício de encaixar partes do "quebra-cabeça" da história de adoecimento do usuário-guia.

O cuidado seguiu a investigação das crises de asma. Foi realizada uma interconsulta com pneumologista e avaliação da apoiadora (fisioterapeuta), constatando-se uma fibrose pulmonar intensa, sem histórico de tabagismo. O laudo da tomografia de crânio apontava lesões no lóbulo frontal, o que levou à hipótese de psicose de origem orgânica.

No exame admissional de saúde ocupacional realizado na empresa constava: pulmões saudáveis. No segundo exame periódico: pequena lesão pulmonar. No terceiro exame periódico: piora considerável da lesão pulmonar. Logo depois veio a demissão e, em seguida, o surto psicótico.

O usuário manipulava substâncias que se solidificavam rapidamente, formando as espumas de estofados para veículos. A composição química continha xileno, tolueno e até benzeno ${ }^{28}$. Foi elaborada a hipótese de inalação prolongada de produtos químicos, factível com sua exposição ocupacional, afastando a hipótese de esquizofrenia.

Nos atendimentos referiu que muitos trabalhadores da empresa, durante o mesmo período, moveram processos judiciais por questões de saúde. Reconstruindo a história laboral foi possível relacionar o período de agravamento do seu problema respiratório com a demissão. A esposa supôs que ele havia aprontado algo no serviço para dar motivação à demissão.

O quadro grave de confusão mental, com discurso fragmentado, e longo histórico de passagens em diferentes serviços da rede de saúde, aparentemente sem progressos e sem recuperação de seu bem-estar social, ganhou novos contornos. A história clínica articulada à trajetória profissional passou a fazer sentido, revelando um transtorno mental orgânico decorrente da exposição a substâncias químicas ${ }^{29}$.

De acordo com Manual das Doenças relacionadas ao Trabalho ${ }^{30}$, o transtorno mental orgânico ou sintomático não-especificado (CID-10 F09) faz parte do grupo de diversos transtornos que inclui, também, a psicose orgânica e a psicose sintomática, e pode ser enquadrado no Grupo I da Classificação de Schilling, em que o trabalho desempenha o papel de causa necessária.

O usuário trabalhava em local insalubre e nenhuma relação causal entre a ocupação e sua doença respiratória e, mais tarde, do transtorno mental com sua atividade laboral havia sido estabelecida $^{31}$. Os inúmeros exames e relatórios médicos, emitidos tanto pela rede de saúde privada como pelo SUS, bem como a documentação médica, demonstravam um processo tortuoso e polifônico, expresso em oito CIDs diferentes nos documentos estudados. A partir da escuta qualificada da apoiadora em saúde ${ }^{25}$ no atendimento em uma UBS, ao dar atenção à fala do usuário sobre o seu trabalho, foi possível produzir uma conexão entre vida e trabalho.

O entrelaçamento da RAPS com a RENAST não é frequente na experiência dos trabalhadores que adoecem no trabalho. Embora tenham origem comum no Movimento Sanitário e nas referências do SUS, mantiveram-se desarticuladas da rede de atenção ${ }^{9}$. O usuário-guia permitiu reconhecer os distanciamentos entre essas duas áreas programáticas e em relação à atenção primária ${ }^{20,32}$.

As redes de atenção no SUS são definidas como estruturas que se integram para a provisão 
de ações e serviços de saúde, institucionalizadas pela política pública em um determinado espaço regional a partir do trabalho planejado de modo coletivo e do aprofundamento das relações de interdependência entre os atores envolvidos ${ }^{33}$. Para construir um trabalho em rede não é suficiente apenas ter equipamentos de saúde distribuídos numa determinada área geográfica ${ }^{34}$.

A prática clínica que não reconhece a categoria trabalho revela uma fragilidade no entendimento e tratamento de diversas psicopatologias ${ }^{35}$. $\mathrm{O}$ usuário-guia teve sua história laboral negligenciada durante muito tempo. A empresa não cumpriu as restrições estabelecidas nos exames ocupacionais. Consequentemente, seus direitos trabalhistas e previdenciários também foram negados. Teve agravamento do seu sofrimento com repercussões importantes sobre sua família, porém acessou o SUS e a escuta atenta e qualificada de seu relato, suas queixas, sua identidade de trabalhador, possibilitou novos agenciamentos.

Outro agravante para suas crises era a saga enfrentada nas perícias trimestrais no INSS, na suspensão do auxílio-doença e parecer de retorno ao trabalho. Foi esse o motivo que o estimulou a solicitar auxílio na UBS: Me ajuda com meu benefício.

Os trabalhadores excluídos do trabalho demandam apoio psicológico em virtude do sofrimento, dos sentimentos de vergonha e passivida$\mathrm{de}^{36}$. A desfiliaçã $0^{37}$ marca a trajetória de exclusão social e a dissolução de vínculos sociais. A privação é o aspecto central da desfiliação no desemprego e as rupturas da sociabilidade contribuem para o isolamento social do desempregado ${ }^{19}$.

\section{Tecendo o cuidado em rede}

A definição de um quadro de psicose orgânica decorrente da exposição laboral possibilitou a reelaboração do PTS, pois o reconhecimento do nexo causal entre o trabalho e o adoecimento ensejaram a revisão dos direitos previdenciários e trabalhistas. O CEREST preencheu a Comunicação de Acidente de Trabalho, repercutindo no semblante do trabalhador, que resplandecia triunfo.

Nos dias seguintes ele passou a apresentar maior asseio pessoal e maior disposição para dar andamento às outras ações coordenadas pelo PTS junto ao CAPS e à UBS. O sentimento de pertencimento e a construção da narrativa da vida são condutores da construção da identidade ${ }^{19}$.

A partir da intervenção da equipe do CAPS, efetuada pela assistente social e pelo psiquiatra, que contataram e questionaram o perito do INSS sobre o caso, o usuário-guia passou a ser melhor entendido no órgão da previdência social. O CAPS e a agência do INSS teceram conexões intersetoriais ${ }^{26,38}$. $O$ benefício não foi mais interrompido, o que o ajudou a se estabilizar, pois assim pôde prover a família. Pouco tempo depois foi aposentado por invalidez pelo INSS, o que the deu tranquilidade, incidindo diretamente sobre seu modo de atuar no mundo ${ }^{21,23}$ e enriqueceu o saber-fazer profissional.

O usuário-guia passou a cuidar de tudo sozinho: da casa, do filho, da sua saúde e da reabilitação da esposa, vítima de um AVC hemorrágico. Continuou a participar das assembleias no CAPS e vinculou-se aos profissionais. O usuário experimentou no passado uma internação psiquiátrica que deixou marcas na sua história. Ao ser inserido no CAPS, dispositivo eficiente no cuidado em saúde mental, tornou-se protagonista no processo de produção de saúde ${ }^{34}$. Começou a frequentar as reuniões de uma associação local que discutia questões de cidadania e geração de renda para pessoas em sofrimento psíquico. As redes vivas proporcionaram a construção compartilhada do cuidado e novas formas de atenção e cuidado em saúde mental ${ }^{18,34}$. Os recursos terapêuticos apostaram no vínculo e na responsabilização e a diversidade de dispositivos impulsionou a inserção em grupos comunitários de caráter emancipatório.

Paralelamente, o CEREST promoveu investigação na empresa a fim de evitar o adoecimento de outros trabalhadores. Este fato confortou o usuário-guia, pois sentiu que pode contribuir com outros companheiros de trabalho. A vigilância em saúde do trabalhador integrou a produção do cuidado em saúde ${ }^{38}$ e contribuiu para ressignificar o sofrimento ético-político ${ }^{39}$ vivenciado pelo usuário. Na dor advinda das injustiças sociais e do estigma de "louco", acessou o cuidado integral em saúde e ampliou seu poder de agir sobre o mundo.

O CEREST realizou apoio matricial em todos os CAPS $^{9}$ da cidade relatando o caso de psicose orgânica como um evento sentinela e orientando sobre a notificação de casos de trabalhadores da mesma empresa, caracterizando um trabalho de busca ativa de novos usuários ${ }^{40}$. Os transtornos mentais relacionados ao trabalho são agravos de notificação compulsória, desde 2004, entre eles, os transtornos orgânicos de personalidade. As notificações são instrumentos essenciais no cuidado integral às pessoas, dão visibilidade às situações, atuam na prevenção de novos casos e na promoção dos direitos dos trabalhadores ${ }^{41}$. 
A biografia do usuário-guia revela o sofrimento apartado da vida concreta do homem trabalhador. Os aspectos orgânicos deflagradores de um transtorno mental foram banalizados ou negligenciados na compreensão do sofrimento que teve origem no seu trabalho. As diversas manifestações de angústia, os problemas respiratórios e as alterações de comportamento, advindas das lesões cerebrais, causaram a perda da identidade, levando a uma vida débil e limitada.

No rastro de muita dor, a perda de referências e a imensa fragmentação levaram o usuário-guia a fazer um diário. As anotações possibilitaram criar alguma linearidade e armazenar as informações que sua mente não conseguia. A equipe de saúde integrada funcionou como organizadora do seu estar no mundo e criou condições para que ele pudesse alinhavar um novo funcionamento do seu aparato mental e dar continuidade à sua vida cotidiana.

A relação empática, humanizada e resolutiva permitiu, a partir da escuta do pedido inicial ajuda para conseguir o benefício no INSS, pois eu preciso sustentar a minha família, circular saberes e práticas e potencializar uma atenção integral ao usuário, expressão do compromisso radical com o usuário-cidadão de direitos.

Cabe destacar que a experiência sobre a articulação do cuidado em rede, incluindo CAPS, CEREST e UBS, estava sendo implantada na rede municipal de saúde naquele período, ${ }^{38,41}$ de acordo com a plano municipal de saúde do trabalhador e da trabalhadora e demais áreas específicas, de modo permanente, porém em construção.

\section{Considerações finais}

$\mathrm{Na}$ narrativa da vida do usuário-guia transparece a conectividade das redes de Atenção Psicossocial e de Saúde do Trabalhador e vislumbram-se as redes vivas de cuidado em saúde, que possibilitam a compreensão multifacetada do estar no mundo dos usuários.
Mostra que equipes de saúde, mobilizadas por um compromisso ético, podem se conectar com as necessidades do usuário e desenhar um cuidado singularizado, operando como um timoneiro em busca da integralidade.

A escuta atenta e respeitosa cria condições de perceber e integrar os diversos determinantes de saúde para além do aspecto clínico. Produz um diagnóstico situacional, em que o sujeito é visto no contexto e nas inter-relações que se estabelecem. A produção social da loucura e sua conexão com a negligência da proteção à saúde nos ambientes de trabalho, com a desconexão entre a política de previdência social e a política de saúde, corrobora a necessidade de engendrar o apoio à formação de redes de cuidado em saúde.

Em tempos de tantos ataques ao SUS podemos destacar que esse padrão de cuidado em saúde, produzido no caso do usuário-guia, não encontra nada semelhante na saúde suplementar. A confluência do aspecto multidisciplinar, da integração de diferentes pontos da atenção em saúde, da intersetorialidade orquestrada pela ênfase na dignidade humana, no direito à vida, ao cuidado em liberdade, e na saúde como direito fundamental aquilatam o valor desta política de saúde. Contar com diretrizes de saúde que olham para o singular e o coletivo atestam a humanização tecida no cotidiano da atenção primária. Os territórios de saúde, com sua micropolítica e capacidade de produzir vínculos, pode ressignificar a vida de pessoas com quadros de adoecimento complexos.

O usuário-guia escancara a complexidade e desafios diários do fazer em saúde. A eficácia e resolutividade do sistema traz satisfação para o usuário, mas também para as equipes de saúde, que veem cumpridas suas expectativas.

Consoante aos estudos atuais em Saúde Mental relacionada ao Trabalho, este artigo ratifica a necessidade de uma clínica contextualizado do trabalho ${ }^{18}$ e contribui para formação de profissionais de saúde na medida em que dialoga com as diretrizes do SUS e as políticas públicas de Saúde Mental e de Saúde do Trabalhador, pautadas no direito à vida, no respeito à dignidade $\mathrm{e}$ no compromisso ético com a saúde das pessoas. 


\section{Colaboradores}

Os autores contribuíram igualmente para a produção do manuscrito.

\section{Referências}

1. Dejours C. A loucura no trabalho. São Paulo: Oboré Editorial; 1987.

2. Seligmann-Silva E. Desgaste mental no trabalho dominado. São Paulo: Cortez; 1994.

3. Silva Junior JS, Fischer FM. Adoecimento mental incapacitante: benefícios previdenciários no Brasil entre 2008-2011. Rev Saude Publica 2014; 48:186-190.

4. Laurell AC, Noriega M. Processo de Produção e Saúde: Trabalho e Desgaste Operário. São Paulo: Hucitec; 1989.

5. Rebouças AJA, Antonaz D, Lacaz FAC, Ribeiro HP, Snelwar LI, Sato L, Freitas NBB, Todeschini R, Kucinski B, Cardoso FC, Toni G. Insalubridade: morte lenta no trabalho. São Paulo: Oboré Editorial; 1989.

6. Lacaz FAC. O campo Saúde do Trabalhador: resgatando conhecimentos e práticas sobre as relações trabalho-saúde. Cad Saude Publica 2007; 23:757-766.

7. Buschinelli JTP, Rocha LE, Rigotto RM. Isto é trabalho de gente?: vida, doença e trabalho no Brasil. São Paulo: Vozes; 1994.

8. Maeno M, Carmo JC. Saúde do Trabalhador no SUS. São Paulo: Hucitec; 2005.

9. Bernardo MH, Garbin AC. A atenção à saúde mental relacionada ao trabalho no SUS: desafios e possibilidades. Rev Bras Saude Ocup 2011; 36(123):103-117.

10. Brasil. Ministério da Saúde (MS). Implantação das Redes de Atenção à Saúde e outras estratégias da SAS. Brasília: MS; 2014.

11. Brasil. Portaria no 2.728 , de 11 de novembro de 2009. Dispõe sobre a Rede Nacional de Atenção Integral à Saúde do Trabalhador e dá outras providências. Diário Oficial da União 2009; 12 nov.

12. Amarante P. Loucos pela vida: a trajetória da reforma psiquiátrica no Brasil. Rio de Janeiro: Fiocruz; 2000.

13. Minayo-Gomez C, Thedim-Costa SMF. A construção do campo da saúde do trabalhador: percurso e dilemas. Cad Saude Publica 1997; 13(Supl. 2):21-32.

14. Amarante P, Torre EHG. A constituição de novas práticas no campo da atenção psicossocial: análise de dois projetos pioneiros na reforma psiquiátrica no Brasil. Saúde Debate 2001; 58:26-34.

15. Gomez CM, Lacaz FAC. Saúde do trabalhador: novasvelhas questões. Cien Saude Colet 2005; 10(4):797807.

16. Cecilio LCO. As necessidades de saúde como conceito estruturante na luta pela integralidade e equidade na atenção em saúde. In. Pinheiro R, Mattos RA de. Os sentidos da integralidade na atenção e no cuidado à saúde. Rio de Janeiro: IMS/ABRASCO; 2001. p. 113 126.

17. Merhy EE, Baduy RS, Seixas CT, Almeida DES, Slomp Júnior H. Avaliação compartilhada do cuidado em saúde: surpreendendo o instituído nas redes. $1^{\text {a }} \mathrm{ed}$. Rio de Janeiro: Hexis; 2016. Livro I.

18. Merhy EE, Gomes MPC, Silva E, Santos MFL, Cruz KT, Franco, TB. Redes Vivas: multiplicidades girando as existências, sinais da rua. Implicações para a produção do cuidado e a produção do conhecimento em saúde. Divulg Saude Debate 2014; (52):153-164. 
19. Seligmann-Silva E. Trabalho e desgaste mental: o direito de ser dono de si mesmo. São Paulo: Cortez; 2011.

20. Lacerda e Silva T, Dias EC, Pessoa VM, Fernandes LMM, Gomes EM. Saúde do trabalhador na Atenção Primária: percepções e práticas de equipes de Saúde da Família. Interface (Botucatu) 2014; 18(49):273-288.

21. Gomes MPC, Merhy EE., organizadores. In-Mundo: um estudo da produção do acesso e barreira em saúde mental. Porto Alegre: Rede UNIDA; 2014.

22. Marques MS, Zanutto CC, Fernandes, JM, Savio TJ, Capozzolo AA. A construção singular do apoio em um território do município de São Bernardo do Campo. In: Merhy EE, Baduy RS, Seixas CT, Almeida DES, Slomp Júnior H. Avaliação compartilhada do cuidado em saúde: surpreendendo o instituído nas redes. $1^{\text {a }} \mathrm{ed}$. Rio de Janeiro: Hexis; 2016. p. 243-251. Livro I.

23. Feuerwerker LCM, Bertussi DC, Merhy EE. Avaliação compartilhada do cuidado em saúde: surpreendendo o instituído nas redes. $1^{\text {a }}$ ed. Rio de Janeiro: Hexis; 2016. Livro II.

24. Czeresnia D. The concept of health and the difference between prevention and promotion. Cad Saude Publica 1999; 15(4):701-709.

25. Reis AAC, Bertussi DC, Fuentes ICP. A gestão do cuidado na rede de saúde em São Bernardo do Campo: enfrentando desafios e tecendo novos arranjos. In: Souza MF, Franco MS, Mendonça AVM. Saúde da família nos municípios brasileiros: os reflexos dos 20 anos do espelho do futuro. Campinas: Saberes; 2014. p. 206242.

26. Sundfeld AC. Apoio como dispositivo: conexões, invenções e provocações à produção coletiva do cuidado e da gestão no município de São Bernardo do Campo [tese]. São Paulo: Universidade de São Paulo; 2016.

27. Campos GWS, Domitti AC. Apoio matricial e equipe de referência: uma metodologia para gestão do trabalho interdisciplinar em saúde. Cad Saude Publica 2007; 23(2):399-407.

28. National Institute for Occupational Safety and Health (NIOSH). Directory of Chemical Safety Resources. [cited 2020 Mar 27]. Available from: https://www.cdc. gov/niosh/topics/chemical.html.

29. International Labour Organization. Work-Related Psychosis Encycoplaedia of Occupational Healthy and Safety. [cited 2020 Abr 16]. Available from: https://www. iloencyclopaedia.org/part-i-47946/mental-health/ item/264-work-related-psychosis.

30. Brasil. Ministério da Saúde (MS). Doenças relacionadas ao trabalho: manual de procedimentos para os serviços de saúde. Brasília: MS; 2001.

31. Jardim S, Glina D. Os diagnósticos dos transtornos mentais relacionados ao trabalho. In: Glina D, Rocha L. Saúde mental no trabalho: Desafios e soluções. São Paulo: VK. p. 17-52.

32. Santos APL, Lacaz FAC. Apoio matricial em saúde do trabalhador: tecendo redes na atenção básica do SUS, o caso de Amparo/SP. Cien Saude Colet 2012; 17(5):1143-1150.
33. Silva SF. Organização das Redes Regionalizadas e Integradas de Atenção à Saúde: desafios do Sistema Único de Saúde (SUS) Brasil. Cien Saude Colet 2011; 16(6):2753-2762.

34. Quinderé PHD, Jorge MSB, Franco TB. Rede de Atenção Psicossocial: qual o lugar da saúde mental?. Physis 2014; 24(1):253-271.

35. Jacques MG. O nexo causal em saúde/doença mental no trabalho: uma demanda para a psicologia. Psicol Soc 2007; 19(n. esp.):112-119.

36. Seligmann-Silva E. Desemprego e Desgaste mental: Desafio às Políticas Públicas e aos Sindicatos. Rev Cienc Trabalho 2015; 4:89-109.

37. Castel R. As Metamorfoses da Questão Social: uma crônica do salário. Petrópolis: Vozes; 1998.

38. Garbin AC, Pintor EAS. Estratégias de intra e intersetorialidade para transversalizar a saúde do trabalhador em todos os níveis de atenção à saúde. Rev Bras Saude Ocup 2019; 44:e18.

39. Sawaia BB. As artimanhas da exclusão: uma análise ético-psicossocial da desigualdade. Petrópolis/RJ: Vozes; 1999.

40. Lacaz FAC. Continuam a adoecer e morrer os trabalhadores: as relações, entraves e desafios para o campo Saúde do Trabalhador. Rev Bras Saude Ocup 2016; 41:e13.

41. Pintor EAS, Garbin AC. Notificações de violência relacionadas ao trabalho e vigilância em saúde do trabalhador: rompendo a invisibilidade. Rev Bras Saude Ocup 2019; 44:e20.

Artigo apresentado em 25/05/2020

Aprovado em 26/07/2021

Versão final apresentada em 28/07/2021

Editores-chefes: Romeu Gomes, Antônio Augusto Moura da Silva 
